\title{
How organic farmers practice conservation agriculture in Europe
}

Joséphine Peigné ${ }^{1 *}$, Marion Casagrande ${ }^{1}$, Vincent Payet $^{1}$, Christophe David ${ }^{1}$, F. Xavier Sans ${ }^{2}$, José M. Blanco-Moreno ${ }^{2}$, Julia Cooper ${ }^{3}$, Kate Gascoyne ${ }^{3}$, Daniele Antichi ${ }^{4}$, Paolo Bàrberi ${ }^{5}$, Federica Bigongiali ${ }^{5}$, Andreas Surböck ${ }^{6}$, Andreas Kranzler ${ }^{6}$, Annelies Beeckman ${ }^{7}$, Koen Willekens ${ }^{8}$, Anne Luik $^{9}$, Darja Matt ${ }^{9}$, Meike Grosse ${ }^{10}$, Juergen He ${ }^{10}$, Maurice Clerc ${ }^{11}$, Hansueli Dierauer ${ }^{11}$ and Paul Mäder ${ }^{11}$

'ISARA Lyon, 23 rue Jean Baldassini, Lyon 69007, France.

${ }^{2}$ Agroecosystems Research Group, IRBio, University of Barcelona, Avda. Diagonal 643, Barcelona 08028, Spain. ${ }^{3}$ Nafferton Ecological Farming Group (NEFG), Newcastle University, Nafferton Farm, Stocksfield NE43 7XD, UK.

${ }^{4}$ Centre for Agro-Environmental Research "Enrico Avanzi”, University of Pisa, Via Vecchia di Marina 6, 56122 San Piero a Grado, Pisa, Italy.

Institute of Life Sciences, Scuola Superiore Sant'Anna, Piazza Martiri della Libertà 33, Pisa 56127, Italy.

${ }^{6}$ Research Institute of Organic Agriculture (FiBL) Austria, Doblhoffgasse 7/10, Wien A-1010, Austria.

7 Inagro, leperseweg 87, Roeselare 8800, Belgium.

${ }^{8}$ Institute for Agricultural and Fisheries Research (ILVO), Plant Sciences Unit, Crop Husbandry and Environment, Burg. Van Gansberghelaan 109, Merelbeke B-9820, Belgium.

${ }^{9}$ Estonian University of Life Sciences (EULS), Kreutzwaldi 1, Tartu 51 014, Estonia.

${ }^{10}$ Department of Organic Farming and Cropping, University of Kassel, Faculty of Organic Agricultural Sciences, Nordbahnhofstr. 1a, Witzenhausen 37123, Germany.

${ }^{11}$ Research Institute of Organic Agriculture (FiBL), Ackerstrasse, Frick CH-5070, Switzerland.

${ }^{*}$ Corresponding author: jpeigne@isara.fr, http://www.isara.fr

\begin{abstract}
The interest of organic farmers in adopting conservation agriculture principles, including minimal soil disturbance, permanent soil cover and crop rotation has been growing since the early 2000s. However, currently there is no network for organic farmers practicing conservation agriculture, and a lack of knowledge on how organic farmers implement conservation agriculture in practice. Consequently, few technical references are available for organic farmers when they start applying conservation agriculture practices, in particular on controlling weeds without the use of herbicides. The main objectives of this study were: (1) to explore the diversity of conservation agriculture techniques (i.e., reduced tillage, notillage and green manures) practiced among European farmers, and (2) to identify farmers' main strategies for implementing conservation agriculture and the agronomic and environmental factors that determine these strategies. Strategies were identified by analyzing survey results on: (1) the type and degree of use of conservation agriculture practices by farmers, and (2) the effects it produces in terms of soil disturbance and soil cover (low, medium and high). We carried out a survey of 159 European organic farmers and collected 125 data sets on management of winter-sown crops. Among the conservation agriculture practices, reduced tillage was used by $89 \%$, no-tillage by $27 \%$ and green manure by $74 \%$ of the 159 interviewed farmers. Green manures were more frequently used in northern Europe than in the south (below $45^{\circ} \mathrm{N}$ ). Most of the farmers used crop rotations, with a mean duration of 6 years. A wide diversity of conservation agriculture practices were used, with farmers rarely using all three techniques (no-till, reduced till and green manures) within one system. The range of practices was grouped into five strategies ranging from intensive non-inversion tillage without soil cover to very innovative techniques with no-tillage and intercrops. The five strategies for conservation agriculture could be grouped into two larger categories based on weed control approach: (1) intensification of the mechanical work without soil inversion or (2) biological regulation of weeds with cover crops. The diversity of strategies identified in this study shows that organic farmers use innovative approaches to implement conservation agriculture without herbicides. This study's findings will help organic farmers to experiment with innovative practices based on conservation
\end{abstract}


agriculture principles and also benefit conventional farmers who use conservation agriculture practices and would like to reduce or eliminate the use of herbicides.

Key words: organic farming, reduced tillage, no-tillage, green manure, mechanical weed control

\section{Introduction}

Agriculture in developed countries faces many challenges such as sustaining food production, minimizing environmental impacts and maintaining economic viability. New forms of agriculture have emerged in recent years addressing these challenges. Organic farming was one of the earliest forms of agriculture which tried to balance the demands of food production with environmental sustainability. The main requirement of organic farming is to prohibit the use of synthetic pesticides and fertilizers. According to the European standards (No. 834/2007), organic farming is based on the conservation of soil fertility and ideally requires a closed farming system that includes plants and animals to facilitate effective recycling of nutrients ${ }^{1}$. However, for socio-economic reasons, the development of organic farming in Europe has led increasingly to systems where the link between plants and animals has been broken, with the increasing abundance of farms specialized either in crop production or in livestock production. This is sometimes referred to as the 'conventionalization' of organic farming and has been denounced by some of the major actors (union of farmers, activists and researchers) within the organic farming movement $t^{2,3}$. This conventionalization undermines the principles of organic agriculture, and further distances organic farming systems from the natural ecosystems they seek to emulate. For example, stockless organic farms often rely on high levels of nutrient imports coupled with high exports which raise concerns about the preservation of closed nutrient cycles ${ }^{4}$.

In parallel with organic farming, new alternative forms of agriculture aimed at preserving the soil and the environment have emerged. One of the best known is conservation agriculture. Conservation agriculture is based on enhancing natural biological processes above and below the ground $^{5}$. Conservation agriculture relies on three main principles: (1) a minimal soil disturbance or absence of deep plowing, (2) a permanent soil cover with green manure during the non-cultivation period and (3) diversification of crops in the rotation (FAO, http://www.fao.org/ $\mathrm{ag} / \mathrm{ca} /)$. The main objective of conservation agriculture is to protect the soil from mechanical and weather-caused disturbances ${ }^{6}$. Minimal soil disturbance, such as notillage or reduced tillage avoiding deep plowing, and green manures, favor soil biodiversity, increase soil organic carbon (SOC) content at the soil surface and minimize erosion ${ }^{7,8}$. Conservation agriculture practices, by integrating minimal soil disturbance with green manure and diverse crop rotations, maximize soil conservation and contribute to a reduction in negative effects from reduced tillage. For example, green manures used as cover crops can control weeds and reduce the need for herbicides that are often used in no-tillage systems. Although the use of diverse crop rotations and green manures commonly used in organic farming systems can reduce weed pressure $^{5}$, weed control remains problematic under no-tillage without the use of synthetic herbicides ${ }^{9}$. As a consequence, many organic farmers are not attracted by conservation agriculture and still rely on deep plowing as their basic weed control measure. A study in France showed that the two farming system communities disagreed on the topic of soil preservation, with proponents of conservation agriculture arguing that the organic farming practices are more damaging to the soil ${ }^{10}$.

Organic farmers are sensitive to these arguments and have recently taken an interest in conservation agriculture $^{11}$. There are many challenges associated with the use of conservation agriculture practices in organic farming, including soil compaction, low nitrogen availability in the spring and sourcing of adapted equipment for controlling weeds ${ }^{12-14}$. Indeed, one of the main obstacles, as described above, is management of weeds without herbicides. Despite these obstacles, pioneering organic farmers have been trying since the early 2000 s to adopt the principles of conservation agriculture ${ }^{11}$.

Several scientific studies have investigated the effects of conservation agriculture practices on soil fertility, weeds and crops in organic arable cropping systems. The main results have shown that reduced tillage in organic farming increases soil carbon content and soil organisms in the topsoil ${ }^{15-17}$. Effects on weeds and crop yields were not as clear, with a tendency for more perennial weeds ${ }^{9}$ and lower yields in reduced tillage compared with plowing $9,18,19$. However, these experiments were often carried out by researchers and based on the comparison of tillage systems only and not conservation agriculture as a combination of several practices. These factor-based studies make it difficult to conclude whether it is possible or not to implement conservation agriculture on organic farms.

Since conservation agriculture involves the implementation of a combination of management practices, which may vary depending on the pedo-climatic zone and farming system, it is valuable to explore the practices actually implemented on farms. The aim of this paper is to explore the diversity of conservation agriculture practices currently implemented by organic farmers in Europe. Through exploration of this diversity, the second objective of our study is to check whether farmers share common strategies when they use conservation agriculture practices and what agronomic and 
environmental factors determine these strategies. A strategy can be defined by: (1) the type and degree of use of conservation agriculture practices by farmers, and (2) the effects it produces in terms of soil disturbance and soil cover (low, medium and high).

\section{Materials and Methods}

\section{The survey}

In 2012, a questionnaire-based survey of 159 organic farmers across ten European countries was conducted. All the Organic farmers interviewed have followed EU regulations (No. 834/2007, http://eur-lex.europa.eu/ LexUriServ/LexUriServ.do?uri=OJ:L:2007:189:0001:0023: EN:PDF) for at least 3 years. The selected countries were partners in the TILMAN-ORG Project (http://www. tilman-org.net/). The farmers included in the survey used green manures, and/or no-tillage and/or reduced tillage for all or part of their arable crop rotation. From the 159 interviews, we collected information on 125 cropping systems applying conservation tillage practices on wintersown crops. The distribution of cropping systems among eight countries was: Estonia (five farmers), Germany (ten farmers), United Kingdom (ten farmers), France (29 farmers), Switzerland (19 farmers), Austria (16 farmers), Italy (three farmers) and Spain (33 farmers).

No-tillage (also called zero tillage) is a conservation tillage practice where the crop is sown directly into soil that has not been tilled since the harvest of the previous crop. Reduced tillage is considered to be any tillage practice shallower than the conventional practice and/or non-inversion of soil such as chisel plowing. A green manure (also called a cover crop) is any crop that is grown primarily or solely for the purpose of soil protection and improvement, including: increasing soil $\mathrm{N}$ supply to the subsequent crop, increasing soil organic matter, reducing weed and pest populations and minimizing soil erosion. Depending on its sowing date, a green manure can also be called an intercrop, if the green manure is sown at the same time as a main crop, or an undersown crop, if it is sown after the main crop establishment. A ley crop in the crop rotation can also be considered as a green manure if at least one cutting is returned to the soil. Fallow periods are not taken into account in this definition.

The survey was carried out with a questionnaire filled out by the farmers themselves, an advisor or a researcher after farmers' interviews. As there is no existing specific network of organic farmers using conservation practices, the farmers were identified using organic agriculture or conservation agriculture networks (agricultural magazines, internet forums, local organizations). This study is thus an exploratory one, aimed at covering a broad (but necessarily partial) spectrum of European organic farmers applying conservation agriculture practices.

\section{The questionnaire}

The questionnaire was divided into two sections: (1) detailed crop management information on one winter crop; and (2) farm description (environment, cropping systems and farmer information).

Crop management practices were described with five successive sections for one winter crop per farmer with a focus on tillage and weeding operations: (1) operations carried out before sowing (green manure management and destruction, pre-crop weeding, stubble cultivation, tillage, etc.); (2) sowing; (3) operations carried out after sowing and before harvest (post-emergence weeding, green manure management such as intersowing or undersowing); (4) harvest; and (5) operations carried out after harvest (stubble cultivation, green manure sowing or destruction). For each operation, farmers detailed: type and date, machinery used and depth of tillage/cultivation. In order to standardize the responses across interviewers, photographs of machinery with a lexicon were provided to the investigators. The questionnaire focused on tillage and green manure management without questions on fertilization, irrigation or natural pesticides used. Although these aspects would be very interesting for characterizing crop management, we preferred to focus on complete and accurate questions on conservation agriculture practices to limit the demands on farmer time required for answering the survey. All the questions and possible answers are detailed in Appendix 1.

To determine all the operations required for winter crop management, farmers answered a set of questions; for instance, Question: 'Do you use green manure before the main crop?' Then farmers answered yes or no. If the farmer answered yes, a second question was: 'What type of green manure do you use?' Proposed answers: legumes, legumes grass, etc. All these variables produced nominal categorical data. We also calculated two additional indicators: soil cover (three classes: low, medium and high, scored to take into account the percentage of months that the soil was covered over the year) and frequency of mechanical weeding (number of passes before and/or during the crop cycle). A winter cereal management was characterized by all of the nominal categorical data recorded in the questionnaire plus values of the two indicators (see Appendix 1). We also collected information related to the farm environment (e.g., location, soil type and climatic condition); the socio-economic characteristics of the farm (e.g., principal type of farming, year of conversion to organic farming). Farmers also described their cropping systems (crop rotation, farm size and areas devoted to main crops) and indicated the sources of information they used for implementing conservation agriculture. All the collected data are presented in Appendix 2.

\section{Statistical analysis}

For analyzing the diversity of crop management practices, we calculated the percentage of farmers who applied each 
possible operation. This descriptive analysis gives an overview of all the possible operations and their application rate.

For characterizing the strategies of winter crop management, we used a multiple correspondence analysis $(\mathrm{MCA})^{20}$. MCA uses a map-like representation of the distribution of a set of winter crop management observations (individuals) using nominal categorical and numeric variables which characterizes the crop management. We clustered them in groups (called strategies) using a hierarchical clustering procedure (HCP). The clustering of the winter crop management observations was performed on the first five components of the MCA. The optimal number of strategies was determined by means of the gain of within-clusters inertia. Then, we identified technical operations and soil indicator variables, which characterize each strategy. For each strategy, we obtained the average level (numeric variables) or the proportion of winter crop management observations employing a given technique (categorical variables), and tested it for difference against the whole sample. If there was significant difference, then the variable was considered to characterize the strategy. Statistical significance of the difference between the strategy and the overall sample was assessed through a statistic $u$ that follows a normal distribution ${ }^{21}$. If this quantity is more extreme than the reference quantile of the normal distribution, then the variable discriminates the group of individuals ( $V$-test with $P$ value $<0.01$ ). We tested all the variables that characterized the winter crop management for differences between the identified strategies and the overall sample.

We also tested whether variables not included in the MCA, such as environment (i.e., country, geographic coordinates), cropping systems (i.e., length of the crop rotation, ratio of grass-clover) and farmers' data (i.e., age, sources of information) differed between strategies. All these supplementary variables are presented in Appendices 1and 2-Tables 1 and 2. These include both nominal (qualitative data) and numeric (quantitative data). These data were statistically tested to find the most important supplementary variables for each strategy $(P$ value $\leqslant 0.05)$.

All statistical analyses were conducted in $\mathrm{R} 2.15 .1$ (R Core Team, 2012) with the R package FactoMine ${ }^{21}$.

\section{Results and Discussion}

\section{Overview of the 159 interviewed farmers}

Details on the cropping systems and the environmental characteristics of the farms and the conservation practices applied by the farmers' sample are given in Table 1 split by geographic regions. Among the major conservation agriculture practices, reduced tillage was used by $89 \%$, no-tillage by $27 \%$ and green manures by $74 \%$ of the 159 interviewed farmers. Sixty-three percent of the 159 interviewed farmers combined reduced tillage and green manures. Only $19 \%$ of the 159 farmers combined notillage and green manures. In terms of frequency, green manures were more common in the northern part of Europe (above $45^{\circ} \mathrm{N}$ ) (Table 1). Only $48 \%$ of the surveyed farmers in Southern Europe (below $45^{\circ} \mathrm{N}$-in our sample 50 farmers from Italy, France and Spain) used green manures compared with $83 \%$ of surveyed farmers located in north-western Europe (above $45^{\circ} \mathrm{N}$ and $<17^{\circ}$ E, $n=80$ ) and $96 \%$ in north-eastern Europe (above $45^{\circ} \mathrm{N}$ and $>17^{\circ} \mathrm{E}, n=29$ ). The 159 farmers had applied no-tillage on average for 5.25 years (SD 4.7 years), reduced tillage on average for 19 years (SD 13 years) and green manures on average for 16 years (SD 9 years). A strong difference was observed between northern and southern parts of Europe for reduced tillage: farmers had used this practice on average for 21 years in the south and only for 4.5 years in the north. Overall, reduced tillage was used more often than no-tillage (Table 1). These results confirm scientific results, which show the difficulty in using no-tillage practices in organic farming due to difficulties with weed control $^{12,13}$. Furthermore, plowing had not been totally abandoned by farmers. The plow was still used for specific crops or in weed-infested fields which were normally managed with no-till or reduced tillage practices. In our survey, the mean frequency of plowing in an otherwise no-till field was 0.06 (i.e., 0.6 times in 10 years), whereas in reduced tillage fields it was 0.20 (two times in 10 years). Thus, in the strict sense of the term, longterm implementation of conservation tillage was very rare in European organic farming systems, with most interviewed farmers adopting a 'hybrid' approach where conventional tillage (inversion plowing) and reduced or no-tillage practices were both used at appropriate stages of the rotation. This could impact on the perceived soil quality benefits of conservation agriculture practices within organic farming systems, since several authors $^{22-24}$ have reported that the reintroduction of plowing in no-till systems destroys the SOC stratification in the soil profile, and disrupts the biological activity, although it does not modify the SOC stock.

Green manures of any type were less well represented in the southern part of Europe in our farmers' sample, probably due to climatic conditions which limit the potential for good establishment outside of the main cropping period (see Table 1). Lower precipitation and higher temperatures in southern Europe tend to increase water shortages for green manures growing during summer and competition for water between the green manure and the main crop when grown together. The scarce use of green manures in areas of southern Europe is a concern in light of the high risk of soil erosion in these areas. Indeed, covering the soil during the fall and winter periods would considerably reduce soil erosion risks on southern European organic farms ${ }^{25}$. Further studies are needed to identify the factors that explain the underuse of green manures in southern Europe, 


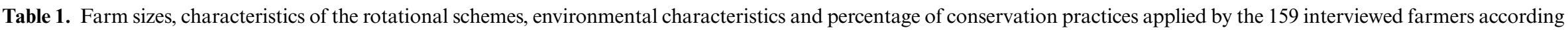
to their geographic location.

\begin{tabular}{|c|c|c|c|c|c|c|c|c|c|}
\hline \multirow{2}{*}{$\begin{array}{l}\text { Geographic location of the interviewed farmers } \\
\text { in Europe } \\
\text { Numbers of farmers }\end{array}$} & \multicolumn{3}{|c|}{$\begin{array}{l}\text { North-west Europe } \\
\left(>45^{\circ} \mathrm{N} \text { and }<17^{\circ} \mathrm{E}\right)\end{array}$} & \multicolumn{3}{|c|}{$\begin{array}{l}\text { North-east Europe } \\
\left(>45^{\circ} \mathrm{N} \text { and }>17^{\circ} \mathrm{E}\right)\end{array}$} & \multicolumn{3}{|c|}{ South Europe $\left(<45^{\circ} N\right)$} \\
\hline & \multicolumn{3}{|c|}{80 farmers } & \multicolumn{3}{|c|}{29 farmers } & \multicolumn{3}{|c|}{$\begin{array}{c}49 \text { farmers South-west } \\
1 \text { farmer South-east }\end{array}$} \\
\hline Countries concerned & \multicolumn{3}{|c|}{$\begin{array}{l}\text { Austria, Belgium, Eire, France, } \\
\text { Germany, } \\
\text { Switzerland, UK }\end{array}$} & \multicolumn{2}{|c|}{ Austria, Estonia } & & \multicolumn{2}{|c|}{ France, Italy, Spain } & \\
\hline \multicolumn{10}{|l|}{ Farm characteristics by location in Europe } \\
\hline & Mean & $\mathrm{SD}$ & Median & Mean & $\mathrm{SD}$ & Median & Mean & $\mathrm{SD}$ & Median \\
\hline Farm size (ha) & 112 & 179 & 48 & 129 & 112 & 88 & 137 & 144 & 80 \\
\hline Rotation length (years) & 6.4 & 1.9 & 6 & 6 & 2.5 & 5 & 5.2 & 2.3 & 5 \\
\hline Grass-clover in ha & 27 & 62 & 6 & 39 & 48 & 17 & 7.5 & 14 & 0 \\
\hline Grain crop in ha & 73 & 101 & 30 & 56 & 41 & 53 & 72 & 109 & 39 \\
\hline Permanent grassland in ha & 14 & 26 & 5 & 29 & 72 & 3 & 11 & 33 & 0 \\
\hline \multicolumn{10}{|l|}{ Environmental characteristics by location in Europe } \\
\hline Mean annual precipitations (mm) & 821 & 151 & 800 & 693 & 78 & 723 & 703 & 128 & 700 \\
\hline Mean annual temperature $\left({ }^{\circ} \mathrm{C}\right)$ & 9.5 & 1.2 & 9.5 & 7.7 & 1.6 & 7 & 13.2 & 1.3 & 13 \\
\hline Altitude (m) & 251 & 207 & 207 & 140 & 132 & 80 & 450 & 203 & 443 \\
\hline \multicolumn{10}{|c|}{ Percentage of farmers applying conservation practices } \\
\hline No-tillage $(\%)$ & 25 & & & 21 & & & 34 & & \\
\hline Reduced tillage $(\%)$ & 92 & & & 66 & & & 98 & & \\
\hline Green manure $(\%)$ & 83 & & & 96 & & & 48 & & \\
\hline
\end{tabular}


Table 2. Percentage of the 125 interviewed farmers applying technical operations (weeding, tillage, green manure, cover crop or intercrop) for their winter crop.

\begin{tabular}{|c|c|c|c|c|c|c|c|c|c|c|c|c|c|c|c|}
\hline & & & Aug. & Sep. & Oct. & Nov. & Dec. & Jan. & Feb. & Mar. & Apr. & May & June & July & Aug. \\
\hline \multicolumn{16}{|c|}{$\%$ of the 125 farmers applying a technical operation } \\
\hline & Green manure & $54 \%$ & & & & & & & & & & & & & \\
\hline & No-tillage & $18 \%$ & & & & & & & & & & & & & \\
\hline \multirow{4}{*}{ Before the main crop } & Tillage with: & $82 \%$ & & & & & & & & & & & & & \\
\hline & Plowing & $20 \%$ & & & & & & & & & & & & & \\
\hline & Non-inversion tillage & $62 \%$ & & & & & & & & & & & & & \\
\hline & Weeding & $57 \%$ & & & & & & & & & & & & & \\
\hline \multirow[t]{2}{*}{ Main crop } & Crop cycle & & & & & & & & & & & & & & \\
\hline & Weeding & $58 \%$ & & & & & & & & & & & & & \\
\hline \multirow[t]{3}{*}{ With the main crop } & Intercropping & & & & & & & & & & & & & & \\
\hline & Sowing with main crop & $14 \%$ & & & & & & & & & & & & & \\
\hline & Undersowing in the crop & $20 \%$ & & & & & & & & & & & & & \\
\hline \multirow[t]{3}{*}{ After the main crop } & Intercrop as green manure & $26 \%$ & & & & & & & & & & & & & \\
\hline & Undersown crop as green manure & & & & & & & & & & & & & & \\
\hline & New green manure after harvest & $26 \%$ & & & & & & & & & & & & & \\
\hline
\end{tabular}

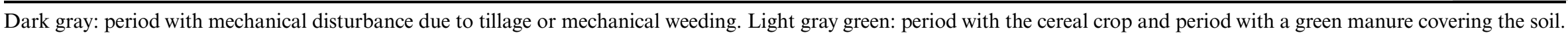


taking into account the negative effect on water availability and the positive effect on soil protection.

\section{The diversity of technical operations $(\mathrm{n}=125)$}

One hundred and twenty-five farmers provided information about winter crops. Ninety-three percent of the main crops were cereals. The previously harvested crop was mostly a cereal such as winter wheat, spelt, barley, oats, millet or maize $(36 \%)$ or a legume such as soybeans, alfalfa or fava bean (29\%). Likewise the following crop was also mostly cereal $(38 \%)$ or legume $(17 \%)$ or a mixture of cereal and legume (12\%). A general overview of all the winter crop management operations is shown in Table 2.

Before main crop sowing, tillage was practiced by $82 \%$ of the 125 farmers, with most using non-inversion methods (62\%; Table 2). Weeding (mainly harrowing) was done by $57 \%$ of the 125 farmers before sowing the main crop. The main crop sowing was done mostly with a combined machine (seeder + rotary harrow) $(85 \%)$ and/or associated with a rolling machine $(32 \%)$, while other tools such as a simple seeder (traditional seeder without rotary harrow) (13\%) or direct seeder (specifically for no-tillage) $(7 \%)$ were less widespread. On average, the 125 farmers practiced 1.5 weeding operations in the winter crop season. Even if conservation tillage practices were used, the majority of organic farmers disturbed the soil with tillage and mechanical weeding. As already mentioned, conservation agriculture practitioners within the European organic farming sector are far from strictly applying the principles of minimum soil disturbance prescribed by the FAO definition.

Fifty-four percent of the 125 farmers sowed a leguminous green manure (i.e., pure legume, legume + cereal, legume + grass, legume + brassica, mixtures) before main crop sowing. For the 68 farmers who sowed green manures, destruction was most commonly achieved by mulching (chopping residue in situ) $(61 \%)$ or mowing $(15 \%)$. Only $2 \%$ used a roller.

Intercropping was not very widespread; only 17 of the 125 farmers $(14 \%)$ sowed an intercrop with the main crop, whereas 25 farmers $(20 \%)$ undersowed during the winter crop cycle. The green manure sown with the winter cereal was left after main crop harvest by 33 farmers $(26 \%)$ or a new green manure was sown after cereal harvest by 33 farmers (26\%). In either case, duration of soil cover with green manures in European organic systems is quite low. This finding reflects the challenges of implementing conservation agriculture systems faced by organic farmers: how to incorporate green manure or control weeds without resorting to deep inversion tillage? Furthermore, many organic farmers use conventional tillage in the intercrop period to help control weeds with false seed bed techniques ${ }^{26,27}$; however, this technique that is not compatible with no-tillage, and more challenging with reduced tillage and cover crop systems.

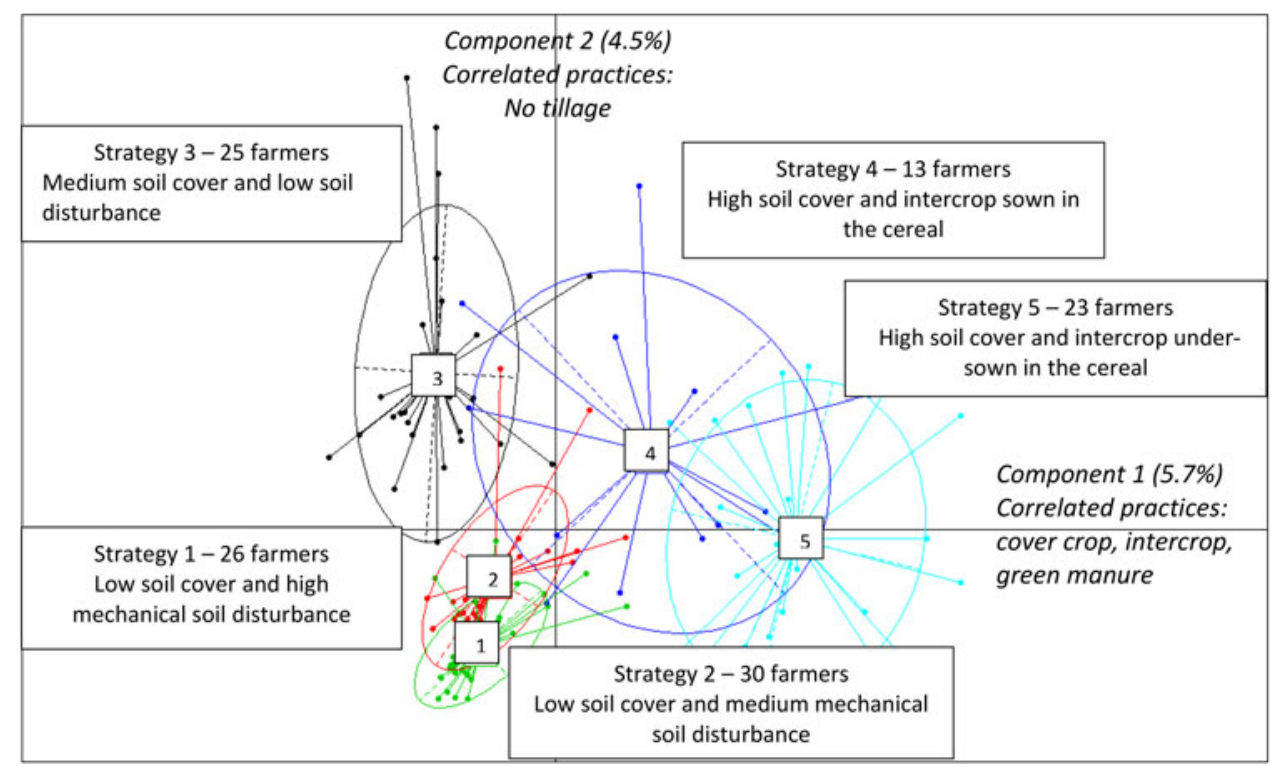

Figure 1. Distribution of the five strategies of winter cereal management in the MCA map. The significant $(P$ value $<0.01)$ technical operations contributing to the factors include tillage application, green manure and intercropping. Factor 1 is significantly explained by green manure after harvest, intercrop (at the same time as the main crop) and green manure management. No-tillage is positively correlated with factor 2. Components 1 and 2 of the MCA explain 5.7 and $4.5 \%$ of the diversity, respectively. The percentage of explained diversity is low. However, as our aim was to find a typology of strategies, MCA just helped us to obtain the best representation of our data. The hierarchical clustering was done on five components (highest explained variability). Five groups have been found. They are shown on the two first components on the figure. Thus overlapping of individuals in several groups is due to the visual representation on two components. 


\section{The main strategies used by European organic farmers}

After a first MCA only farmers growing winter cereals as a main crop were analyzed (117 using winter crop management). The remaining farmers were clearly discriminated based on the crop type (vegetables). A second MCA followed by a hierarchical clustering was conducted. According to the HCP, the 117 winter cereal farmers could be grouped into five clusters (Fig. 1). These groups represented five different strategies for winter crop management (Fig. 1 and Table 3).

The first strategy was mainly characterized by high mechanical soil disturbance $(96 \%$ of the 26 farmers used tillage) and higher total weeding frequency (2.2 operations per year) than the other strategies (Table 3). These farmers did not use intercropping and green manure after the cereal harvest, resulting in a low duration of soil cover. In strategy 1, 13 out of 26 farmers were from Spain.

The second strategy was mainly characterized by medium amounts of mechanical soil disturbance such as harrowing or stubble cultivation and non-inversion tillage (Table 3). Farmers did not use intercropping, and only $27 \%$ of the 30 farmers planted a green manure after the cereal harvest, resulting in a low duration of soil cover (Tables 2 and 3). Seventeen out of the 30 strategy 2 farmers were from Spain. Thus, farms were located on average at higher altitudes and generally further south than farms within the other strategies. The proportion of grass-clover in the crop rotation was low in this group ( $9 \%$ of all the crops in the crop rotation).

The third strategy was mainly characterized by crop management with low soil disturbance before sowing, with $32 \%$ of the 25 farmers using no-till practices (Table 3). It was also characterized by medium duration of soil cover, with a widespread use $(92 \%$ of the 25 farmers) of green manure sown after harvesting the main crop (Tables 2 and 3). Rotation was longer (on average 7 years) in this strategy compared with the other strategies.

The fourth strategy was mainly characterized by long duration of soil cover and use of leguminous intercrops sown with the cereal (Table 3). The intercrop was not harvested with the cereal and was allowed to persist as a green manure (Table 3). The intensive use of intercrops persisting as green manures resulted in a generally long duration of soil cover. These farms were generally located in Eastern Europe.

The fifth strategy was mainly characterized by long duration of soil cover and undersowing after the main crop establishment or before harvest (Table 3). Undersown intercrops were left to persist as green manures after main crop harvest (also called relay intercropping), resulting in a long duration of soil cover (Tables 2 and 3). Because of the high soil cover, the weeding frequency was low (one operation) compared with other strategies. Farms were more often located in northern Europe and at a lower altitude compared with other strategies. These farmers used more sources of information, mainly the Internet, compared to the farmers belonging to the other strategies.

The results for strategy groupings were confounded by issues of geography and culture. The sample of 117 farmers using winter-sown crop management was not well balanced, representing more than 30 French farmers and only three Italian farmers. Consequently, the majority of farms at high altitudes were located in southern Europe. These were the same farmers found to underutilize green manures; however, it is not clear whether this was due to the high altitudes and southern climate, or whether it was related to their lack of access to information, since they were also a group who were less informed than the northern group. In contrast, very innovative practices were found in strategy 5, where farmers were more localized in northern Europe and at lower altitudes, with more access to information. We also found that farmers coming from the same country adopted a certain strategy, for instance all the Spanish farmers were either in strategies 1 or 2. Cultural effects, such as knowledge dissemination in a country or trends in adoption of new techniques or machines, could also explain the choice of a strategy.

\section{Efficiency of farmers' strategies for preserving soil quality and yield stability}

The diversity of strategies shows that organic farmers are innovatively adapting conservation agriculture for systems without herbicides. Considering that weed control is the main challenge in conservation agriculture in organic farming, adopted strategies are based on two distinctive technical approaches: (1) intensification of mechanical intervention without soil inversion for weed control; or (2) biological regulation of weeds by green manures. This biological regulation of weeds can be achieved by inhibiting the germination of weed seeds (due to environment modification, allelopathy) or by direct competition for resources by the green manure.

\section{Intensive non-inversion tillage}

Strategies 1 and 2 rely mainly on low soil cover with noninversion tillage and high-frequency mechanical weeding and/or deep tillage for weed control. The majority of these farmers come from Spain. The implementation of these strategies has consequences for energy consumption and labor inputs, weed control and crop yields. But concerning the overall aims of conservation agriculture, the most important question is: are these strategies efficient in terms of soil preservation? Several studies show that the main positive effect of tillage without soil inversion is the stratification of the soil organic matter, with more organic matter and microbial biomass at the soil 
Table 3. Characterization of the five strategies of winter cereal management according to environmental data, percentage of crop managements which use specific practices in each strategy, cropping system and farmer data.

\begin{tabular}{|c|c|c|c|c|c|}
\hline $\begin{array}{l}\text { Strategy of winter cereal } \\
\text { management }\end{array}$ & $\begin{array}{l}\text { Strategy 1: High } \\
\text { mechanical soil } \\
\text { disturbance and low soil } \\
\text { cover }\end{array}$ & $\begin{array}{l}\text { Strategy 2: Medium } \\
\text { mechanical soil } \\
\text { disturbance } \\
\text { and low soil cover }\end{array}$ & $\begin{array}{l}\text { Strategy 3: Low soil } \\
\text { disturbance and medium } \\
\text { soil cover }\end{array}$ & $\begin{array}{l}\text { Strategy 4: High soil } \\
\text { cover and intercrop sown } \\
\text { with the cereal }\end{array}$ & $\begin{array}{l}\text { Strategy 5: High soil } \\
\text { cover with intercrop } \\
\text { under-sown in the cereal }\end{array}$ \\
\hline Number of managements & 26 & 30 & 25 & 13 & 23 \\
\hline \multicolumn{6}{|l|}{ Environmental data } \\
\hline Coordinates & & South Europe & & East Europe & North Europe \\
\hline Altitude & & High & & & Low \\
\hline \multicolumn{6}{|l|}{ Winter cereal management } \\
\hline $\begin{array}{l}\text { Management before the } \\
\text { main cereal }\end{array}$ & $\begin{array}{l}96 \% \text { of green manure, } \\
84 \% \text { of high weeding } \\
\text { frequency, } 96 \% \text { tillage } \\
\text { before main crop }\end{array}$ & $\begin{array}{l}94 \% \text { without green } \\
\text { manure, } 83 \% \text { of } \\
\text { stubble cultivation/ } \\
\text { harrowing, } 96 \% \text { tillage, } \\
83 \% \text { non-inversion } \\
\text { tillage, } 33 \% \text { deep non- } \\
\text { inversion tillage }\end{array}$ & $\begin{array}{l}76 \% \text { of low weeding } \\
\text { frequency }\end{array}$ & & \\
\hline Sowing of the main cereal & & & $32 \%$ of no-tillage & & \\
\hline $\begin{array}{l}\text { Management of the main } \\
\text { cereal }\end{array}$ & $100 \%$ no intercrop & $96 \%$ no intercrop & $100 \%$ of no intercrop & $\begin{array}{l}100 \% \text { of intercrop sown } \\
\text { with the main cereal, } \\
76 \% \text { leguminous }\end{array}$ & $\begin{array}{l}86 \% \text { of intercrop under- } \\
\text { sown in the cereal }\end{array}$ \\
\hline $\begin{array}{l}\text { Management after the } \\
\text { harvest of the main } \\
\text { cereal }\end{array}$ & $100 \%$ no green manure & $73 \%$ no green manure & $\begin{array}{l}92 \% \text { sown a green } \\
\text { manure after the } \\
\text { harvest }\end{array}$ & $\begin{array}{l}61 \% \text { of the intercrop left } \\
\text { as green manure after } \\
\text { the cereal harvest }\end{array}$ & $\begin{array}{l}86 \% \text { of the intercrop left } \\
\text { as green manure after } \\
\text { the cereal harvest }\end{array}$ \\
\hline \multicolumn{6}{|l|}{ Cropping system data } \\
\hline $\begin{array}{l}\text { Duration of soil cover } \\
\text { (low, medium and } \\
\text { high) }\end{array}$ & $73 \%$ low & $73 \%$ low & Medium & $61 \%$ high & $100 \%$ high \\
\hline Weeding frequency & 2.2 passages & & & & 1 passage \\
\hline $\begin{array}{l}\text { Ratio of grass-clover in } \\
\text { the rotation }\end{array}$ & & Low & & & \\
\hline Rotation length & & & 7 years & & \\
\hline \multicolumn{6}{|l|}{ Farmer data } \\
\hline $\begin{array}{l}\text { Number of sources of } \\
\text { information }\end{array}$ & & & - & & $\begin{array}{l}\text { More sources of } \\
\text { information (mainly } \\
\text { Internet) }\end{array}$ \\
\hline
\end{tabular}

All the data statistically characterize a strategy $(V$-test with a $P$ value $<0.01)$. 
surface ${ }^{17,28}$. This high content of soil organic matter at the soil surface tends to minimize soil erosion. However, the absence of a cover crop and the degraded soil surface structure produced by intensive non-inversion tillage tend to limit this benefit. Regarding soil macro-organisms, no unequivocal conclusion exists in organic farming conditions. For instance, chiseling did not systematically increase earthworm biomass compared to plowing in French trials ${ }^{16}$, but had distinctly positive effects on earthworm populations in another Swiss trial $^{29}$. The timing of tillage operations is also essential in view of detrimental effects on earthworms. As they have a distinct seasonal pattern in their activities in the upper soil layers, tillage operations in the dry and cold season when earthworms move deeper in the soil profile may be less harmful to earthworms in the temperate climatic zone.

Few studies exist on the effects of conservation agriculture practices in organic farming systems on energy consumption and labor inputs, but some results show that there is no gain with intensive non-inversion tillage (two or three passages of chisel) compared to plowing ${ }^{30}$. Nevertheless, the replacement of fall plowing with several tillage operations allows a redistribution of labor and a reduction in labor peaks frequently associated with autumn plowing. Likewise, soil conditions for working are often more favorable for reduced tillage compared to plowing, which extends the period when tillage activities can take place.

Effects on weeds and crop yields of intensive non-inversion tillage in organic farming systems are less clear. According to Armengot et al. ${ }^{31}$, weed abundance was 2.3 times (on average) higher under reduced tillage compared to plowing in a 10-year experiment, and there was no systematic increase with time. However, the average abundance of perennials almost doubled over time under reduced tillage. Despite the weed increase, yields were similar for reduced tillage and plowing. These results confirm previous studies done on the same experiment $^{9,13,15,18}$. However, results obtained in France for reduced tillage are less encouraging. Owing to soil compaction and weed infestation, reduced tillage tended to lower crop performance ${ }^{30,32}$. In terms of crop quality, no effect of reduced tillage in organic farming was found on wheat quality and safety (content of mycotoxin Deoxynivalenol) in various situations ${ }^{32}$.

Intensive non-inversion tillage in southern European conditions allows incorporation of liquid and solid farmyard manure, and this reduces gaseous losses in the form of ammonia. Since ammonia losses from surface-applied manures are a major issue in hot, dry climates, the use of some tillage is justified, especially in organic systems where manure inputs are frequently used ${ }^{33}$. Thus, even if the soil preservation objective is not totally achieved, adoption of intensive non-inversion tillage strategies could be a first step toward implementation of conservation agriculture in organic farming in southern
European regions. These techniques should still increase SOC in the topsoil layer, which was found to be higher in organic agriculture as compared to conventional agriculture in a meta-analysis ${ }^{34}$. Strategies 1 and 2 therefore represent a reasonable compromise between soil preservation and yield stability, particularly in environments not favorable for no-tillage and green manure use.

\section{Biological regulation}

Strategies 3 (based on no-tillage and traditional green manure), 4 and 5 (based on intercropping) rely mainly on biological regulation of weed populations. Indeed, longer crop rotations for strategy 3 and high soil coverage for strategies 4 and 5 improve weed control by: (1) interrupting weed cycles with alternation of winter and spring crops in the rotation; (2) increasing the competition between the weeds and the green manure during the intercrop period. The choice of the green manure crop can also be used for controlling weeds by allelopathy, i.e., rye as green manure is known for its allelopathic effect on weeds ${ }^{35}$. The use of green manure enhances soil fertility ${ }^{36}$. In terms of soil organic matter and soil biodiversity, a green manure tends to stabilize or increase SOC content, and thus provides food for all the living organisms in the soil. Moreover, green manures act on living organisms' habitats by improving soil structure, aggregate stability and soil water retention. Few studies exist on the effects of intercrops and undersown crops on weed control and crop yields in organic farming ${ }^{37,38}$. Understanding the outcome of competitive and synergistic processes between main and secondary crops is a great challenge. Although the use of leguminous cover crops enhances nitrogen supply, the competition for resources (light, water and nutrients) between crops still remains poorly understood.

The main challenge associated with the use of green manures and intercrops in conservation agriculture systems in organic farming concerns their termination without plowing. Indeed, in conventional agriculture, the termination of green manures with no-tillage systems necessitates herbicide use. Only mechanical, physical (e.g., flaming) and climatic (winter-kill) termination can be used in organic farming. This is why the use of green manures and intercrops in organic farming is less widespread and still needs further research. In the USA, notillage and green manures are more often associated with the use of the roller crimper for controlling weeds in organic farming ${ }^{19}$. Only $2 \%$ of the interviewed European farmers used a roller for terminating the green manure and few studies exist in European climatic conditions on this technique. Researchers showed that direct drilling in a rolled green manure left as a cover crop in organic farming conditions highly increased earthworm biomass compared to other tillage systems ${ }^{16}$. However, the yield decreased drastically due to increased competition from weeds and the cover crop if it was not effectively destroyed by the roller ${ }^{30,39,40}$. 


\section{Conclusions}

Regarding conservation agriculture principles, the combination of no or reduced tillage and green manure is not widely applied in organic farming. Farmers still sometimes use the plow in the crop rotation, especially for incorporation of the ley phase of the rotation or the green manure. Nevertheless, a wide diversity of conservation agriculture practices exists within the organic farming community in Europe. These can be grouped into five strategies ranging from intensive tillage without soil cover (far from conservation agriculture principles) to very innovative techniques with no-tillage and intercrops (closer to conservation agriculture principles). Geographic location, cropping systems and sources of information are the main external variables which correlate to strategies. The diversity of strategies shows that organic farmers use innovative approaches to implement conservation agriculture without herbicides. Strategies encountered are mainly based on two distinctive technical options: (1) intensive non-inversion tillage; or (2) biological regulation with green manures. The identification of innovative crop management strategies revealed by our study is the first step toward designing new organic cropping systems that integrate conservation agriculture principles in a more systematic way. As a second step, experiments taking into account these innovations should be set up to monitor effects on soil quality and stability of yields in the long term. These experiments will help organic farmers who are applying conservation agriculture, and also conventional farmers who use conservation agriculture practices and would like to move to more sustainable systems by reducing or eliminating the use of herbicides.

Acknowledgements. This research was carried out within the frame of TILMAN-ORG project (http://www.tilman-org. net) funded by CORE Organic II Funding Bodies, being partners of the FP7 ERANet (http://www.coreorganic2. org). The authors would like to thank Mathieu Guérin, Monica Stanica-Negrescu, Teatske Bakker, Anne Brogi, Lisa Nilles, Rethy Katalin and the interviewed European farmers.

\section{References}

1 Watson, C.A., Atkinson, D., Gosling, P., Jackson, L.R., and Rayns, F.W. 2002. Managing soil fertility in organic farming systems. Soil Use and Management 18:239-247.

2 Darnhofer, I., Bellon, S., Dedieu, B., and Milestad, R. 2010. Adaptiveness to enhance the sustainability of farming systems. A review. Agronomy for Sustainable Development 30:545-555.

3 Goldberger, J.R. 2011. Conventionalization, civic engagement, and the sustainability of organic agriculture. Journal of Rural Studies 27:288-296.

4 Best, H. 2008. Organic agriculture and the conventionalization hypothesis: A case study from West Germany. Agriculture and Human Values 25:95-106.
5 Kassam, A., Friedrich, T., Shaxson, F., and Pretty, J. 2009. The spread of Conservation Agriculture: Justification, sustainability and uptake. International Journal of Agricultural Sustainability 7(4):292-320.

6 Hobbs, P.R., Sayre, K., and Gupta, R. 2008. The role of conservation agriculture in sustainable agriculture. Philosophical Transactions of the Royal Society B: Biological Sciences 363:543-555.

7 Holland, J.M. 2004. The environmental consequences of adopting conservation tillage in Europe: Reviewing the evidence. Agriculture, Ecosystems \& Environment 103: $1-25$.

8 Sapkota, T.B., Mazzoncini, M., Bàrberi, P., Antichi, D., and Silvestri, N. 2012. Fifteen years of no till increase soil organic matter, microbial biomass and arthropod diversity in cover crop-based arable cropping systems. Agronomy for Sustainable Development 32: 853-863.

9 Sans, F.X., Berner, A., Armengot, L., and Mäder, P. 2001. Tillage effects on weed communities in an organic winter wheat-sunflower-spelt cropping sequence. Weed Research 51:413-41.

10 Fleury, P., Chazoule, C., and Peigné, J. 2014. Ruptures et transversalités entre agriculture biologique et agriculture de conservation. Économie rurale 339-340:95-112 (in French).

11 Lefèvre, V., Capitaine, M., Peigné, J., and RogerEstrade, J. 2012. Soil conservation practices in organic farming: Overview of French farmers' experiences and contribution to future cropping systems design. In Proceedings of the 10th European IFSA Symposium, Aarhus, Denmark.

12 Peigné, J., Ball, B.C., Roger-Estrade, J., and David, C. 2007. Is conservation tillage suitable for organic farming? A review. Soil Use and Management 23:129-144.

13 Mäder, P. and Berner, A. 2012. Development of reduced tillage systems in organic farming in Europe. Renewable Agriculture and Food Systems 27:7-11.

14 Casagrande, M., Peigné, J., Payet, V., Mäder, P., Sans, F.X., Blanco-Moreno, J.M., Antichi, D., Bàrberi, P., Beeckman, A., Bigongiali, F., Cooper, J., Dierauer, H., Gascoyne, K., Grosse, M., Heß, J., Kranzler, A., Luik, A., Peetsmann, E., Surböck, A., Willekens, K., and David, C. 2014. Organic farmers in Europe: motivations and problems for using conservation agriculture practices. In G. Rahmann and U. Aksoy (eds). Proceedings of the 4th of ISOFAR Scientific Conference at the Organic World Congress, October 13-15, Istanbul, Turkey. Thünen Report 20, Braunschweig, Germany. Vol. 1, p. 295-298.

15 Berner, A., Hildermann, I., Fliesbach, A., Pfiffner, L., Niggli, U., and Mäder, P. 2008. Crop yield and soil fertility response to reduced tillage under organic management. Soil and Tillage Research 101:89-96.

16 Peigné, J., Cannavaciuolo, M., Gautronneau, Y., Aveline, A., Giteau, J.L., and Cluzeau, D. 2009. Earthworm populations under different tillage systems in organic farming. Soil and Tillage Research 104:207-214.

17 Vian, J.F., Peigné, J., Chaussod, R., and Roger-Estrade, J. 2009. Effects of four tillage systems on soil structure and soil microbial biomass in organic farming. Soil Use and Management 25:1-10. 
18 Krauss, M., Berner, A., Burger, D., Wiemken, A., Niggli, U., and Mäder, P. 2010. Reduced tillage in temperate organic farming: Implications for crop management and forage production. Soil Use and Management 26:12-20.

19 Carr, P.M., Anderson, R.L., Lawley, Y.E., Miller, P.R., and Zwinger, S.F. 2012. Organic zero-till in the northern US Great Plains Region: Opportunities and obstacles. Renewable Agriculture and Food Systems 27: 12-20.

20 Tenenhaus, M., and Young, F.W. 1985. An analysis and synthesis of multiple correspondence analysis, optimal scaling, dual scaling, homogeneity analysis and other methods for quantifying categorical multivariate data. Psychometrika 50:91-119.

21 Lê, S., Josse, J., and Husson, F. 2008. FactoMineR: An R package for multivariate analysis. Journal of Statistical Software 25:1-18.

22 López-Garrido, R., Madejón, E., Murillo, J.M., and Moreno, F. 2011. Soil quality alteration by mouldboard ploughing in a commercial farm devoted to no-tillage under Mediterranean conditions. Agriculture, Ecosystems \& Environment 140:182-190.

23 Melero, S., Panettieri, M., Madejón, E., Macpherson, H. G., Moreno, F., and Murillo, J.M. 2011. Implementation of chiselling and mouldboard ploughing in soil after 8 years of no-till management in SW, Spain: Effect on soil quality. Soil and Tillage Research 112:107-113.

24 Dimassi, B., Cohan, J.-P., Labreuche, J., and Mary, B. 2013. Changes in soil carbon and nitrogen following tillage conversion in a long-term experiment in Northern France. Agriculture, Ecosystems \& Environment 169:12-20.

25 Soane, B.D., Ball, B.C., Arvidsson, J., Basch, G., Moreno, F., and Roger-Estrade, J. 2012. No-till in northern, western and south-western Europe: A review of problems and opportunities for crop production and the environment. Soil Tillage and Research 118:66-87.

26 Bond, W., and Grundy, A.C. 2001. Non-chemical weed management in organic farming systems. Weed Research 41:383-405.

27 Bàrberi, P. 2002. Weed management in organic agriculture: Are we addressing the right issues? Weed Research 42:177-193.

28 Gadermaier, F., Berner, A., Fließbach, A., Friedel, J.K., and Mäder, P. 2012. Impact of reduced tillage on soil organic carbon and nutrient budgets under organic farming. Renewable Agriculture and Food Systems 27: 68-80.

29 Kuntz, M., Berner, A., Gattinger, A., Scholberg, J.M., Mäder, P., and Pfiffner, L. 2013. Influence of reduced tillage on earthworm and microbial communities under organic arable farming. Pedobiologia 56:251-260.
30 Peigné, J., Védie, H., Demeusy, J., Gerber, M., Vian, J.F., Gautronneau, Y., Cannavaccuiolo, M., Aveline, A., Giteau, J.L., and Berry, D. 2009. Techniques sans labour en agriculture biologique. Innovations Agronomiques 4:23-32.

31 Armengot, L., Berner, A., Blanco-Moreno, J.M., Mäder, P., and Sans, F.X. 2014. Long-term feasibility of reduced tillage in organic farming. Agronomy for Sustainable Development. doi: 10.1007/s13593-0140249-y.

32 Peigné, J., Messmer, M., Aveline, A., Berner, A., Mäder, P., Carcea, M., Narducci, V., Samson, M.F., Thomsen, I.K., Celette, F., and David, C. 2013. Wheat yield and quality as influenced by reduced tillage in organic farming. Organic Agriculture 4:1-13.

33 Carozzi, M., Ferrara, R.M., Rana, G., and Acutis, M. 2013. Evaluation of mitigation strategies to reduce ammonia losses from slurry fertilisation on arable lands. Science of the Total Environment 449:126-133.

34 Gattinger, A., Muller, A., Haeni, M., Skinner, C., Fliessbach, A., Buchmann, N., Mäder, P., Stolze, M., El-Hage Scialabbad, N., and Niggli, U. 2012. Enhanced top soil carbon stocks under organic farming. Proceedings of the National Academy of Sciences of the United States of America 109:18226-18231.

35 Teasdale, J.R., Rice, C.P., Cai, G., and Mangum, R.W. 2012. Expression of allelopathy in the soil environment: Soil concentration and activity of benzoxazinoid compounds released by rye cover crop residue. Plant Ecology 213:1893-1905.

36 Scholberg, J.M.S., Dogliotti, S., Leoni, C., Cherr, C.M., Zotarelli, L., and Rossing, W.A.H. 2010. Cover crops for sustainable agrosystems in the Americas. In Genetic Engineering, Biofertilisation, Soil Quality and Organic Farming. Sustainable Agriculture Reviews 4:23-58.

37 Amossé, C., Jeuffroy, M.-H., Celette, F., and David, C. 2013. Relay-intercropped forage legumes help to control weeds in organic grain production. European Journal of Agronomy 49:158-167.

38 Corre-Hellou, G., Dibet, A., Hauggaard-Nielsen, H., Crozat, Y., Gooding, M., Ambus, P., and Jensen, E.S. 2011. The competitive ability of pea-barley intercrops against weeds and the interactions with crop productivity and soil N availability. Field Crops Research 122:264-272.

39 Thorsted, M.D., Weiner, J., and Olesen, J.E. 2006. Aboveand below-ground competition between intercropped winter wheat Triticum aestivum and white clover Trifolium repens. Journal of Applied Ecology 43:237-245.

40 Hiltbrunner, J., Liedgens, M., Bloch, L., Stamp, P., and Streit, B. 2007. Legume cover crops as living mulches for winter wheat: Components of biomass and the control of weeds. European Journal of Agronomy 26: 21-29. 
Appendix 1. The questionnaire with all the questions regarding winter sown crop management, answers and their classification as variables'

\section{Questions}

Name of the crop(s)

Preceding crop(s)

Following crop(s)

Operations before sowing the main crop

1- Green manure management before sowing the main crop

Do you apply any green manure management before sowing?

If yes, what is the species of the green manure?

If yes, what kind of green manure management do you apply?

2- Stubble cultivation before sowing the main crop

Do you apply any stubble cultivation before sowing?

3- Tillage before sowing the main crop

Do you apply any primary tillage operation before sowing?

If yes, what type of tillage operation do you apply?

4- Weeding before sowing the main crop

Do you apply any weeding operation before sowing?

5- Other operations before sowing the main crop

Do you apply any weeding operation before sowing?

\section{Main crop establishment}

When do you sow or plant the main crop?

Do you use combined machines for seed bed preparation and sowing/ planting?

If yes, do you use rotating machines such rotary harrow?

Do you sow an intercrop in the same time as the main crop?

If yes, is the intercrop sown as a green manure or as a second crop?

If yes, what is the species of the intercrop?

If yes, what kind of sowing method do you apply?

Operations after sowing the main crop and before harvest

1 - Weeding after sowing

Do you apply any weeding operation after sowing?

2- Intercrop undersowing

Do you sow an intercrop after sowing the main crop?

If yes, is the intercrop sown as a green manure or as a second crop?

If yes, when do you sow the intercrop?

If yes, what is the species of the intercrop?

If yes, what kind of sowing method do you apply?

3- Other operations after sowing (and before harvest of the main crop)

Do you apply any other operation before harvest that is related either to intercrop crop management or to soil management?
Level (possible answers

to the question)

All possible crops

All possible crops

All possible crops

Type of

variable

Nominal

Nominal

Nominal

Yes or no

If yes, when (date)

All possible crops

Grinding, mowing, rolling, other

Yes or no

If yes, when (date)

Yes or no

If yes, when (date)

Plowing

Depth of plowing

Non-inversion techniques

Depth of non-inversion techniques

Yes or no

If yes, when (date)

Yes or no

If yes, when (date)

If yes, please describe

Date

Yes or no

If no, what type of tool do you use?

Yes or no

Yes or no

Green manure or second crop

All possible species

Broadcast sowing or row sowing or other

Yes or no

If yes, when (date)

If yes, indicate the machine

Yes or no

Green manure or second crop

Soon after the main crop or before harvesting the main crop

When (date)?

All possible species

Broadcast sowing or row sowing or other

Yes or no

If yes, please describe
Categorical

Categorical

Nominal

Nominal

Categorical

Categorical

Nominal

Categorical

Nominal

Categorical

Numeric

Categorical

Numeric

Categorical

Nominal

Categorical

Nominal

Nominal

Nominal

Categorical

Nominal

Categorical

Categorical

Categorical

Nominal

Categorical

Categorical

Nominal

Nominal

Categorical

Categorical

Categorical

Nominal

Nominal

Categorical

Nominal 
Appendix 1. (Cont.)

Level (possible answers

Type of

to the question) variable

Harvest

When do you harvest the main crop?

Date

Nominal

When do you harvest the intercrop (if applicable)?

Date

Nominal

Operations after harvesting the main crop

1- Stubble-plow after the harvest

Do you apply any stubble-plow after sowing?

Yes or no

Categorical

If yes, when (date)

Nominal

2- Green manure management after harvest

Is there already an existing green manure as cover crop on the field?

Yes or no

Categorical

If yes, when do you apply the green manure operation

Date

Nomina

If yes, what king of green manure management do you apply?

If there is no existing green manure, do you sow a green manure?

If you sow a green manure what is the species of the green manure?

Grinding, mowing, rolling, other

Categorical

Yes or no

Categorical

If yes, when (date)

Nominal

All possible crops

Nominal

If you sow a green manure, what kind of sowing method do you apply?

Broadcast sowing or row sowing or

Categorical

If you sow a green manure, when do you apply green manure management? other

Nominal If you sow a green manure, what kind of management do you apply?

Date

Categorical

Appendix 2. The detailed questionnaire with all the questions regarding farm environment, cropping systems and farmer information, possible answers and their classification as variables.

\begin{tabular}{|c|c|c|}
\hline Information of the farm environment & Possible answers & $\begin{array}{l}\text { Type } \\
\text { variable }\end{array}$ \\
\hline Country & List of the ten countries & Nominal \\
\hline Longitude (degrees) & & Numeric \\
\hline Latitude (degrees) & & Numeric \\
\hline Altitude (m) & & Numeric \\
\hline Mean annual precipitation (mm) & & Numeric \\
\hline Mean annual temperature $\left({ }^{\circ} \mathrm{C}\right)$ & & Numeric \\
\hline Soil types & Clay, Loamy, Sandy, Silty soils or mixed soil & Nominal \\
\hline \multicolumn{3}{|l|}{ Information on the cropping systems } \\
\hline Total farmland in ha & & Numeric \\
\hline Total grass-clover in ha & & Numeric \\
\hline Total arable land in ha & & Numeric \\
\hline Total permanent grassland in ha & & Numeric \\
\hline Total ecological compensation areas in ha & & Numeric \\
\hline Main economical orientation & $\begin{array}{l}\text { Arable, vegetables, permanent crops, livestock systems or } \\
\text { mixed systems }\end{array}$ & Nominal \\
\hline Duration of the crop rotation in years & & Numeric \\
\hline \multicolumn{3}{|l|}{ Information on the farmer } \\
\hline Date of conversion to organic farming in years & & Numeric \\
\hline $\begin{array}{l}\text { Number of sources of information for conservation } \\
\text { agriculture }\end{array}$ & & Numeric \\
\hline $\begin{array}{l}\text { Types of sources of information for conservation } \\
\text { agriculture }\end{array}$ & Advisors, Internet, literature, courses, experiences & Nominal \\
\hline
\end{tabular}

